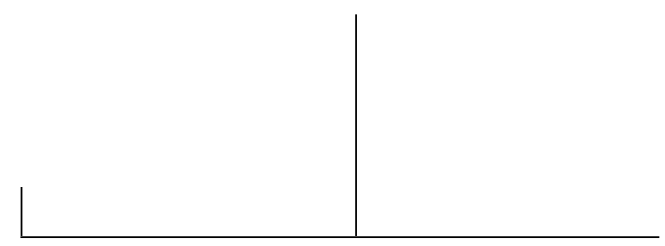

Rev. Latinoam. Psicopat. Fund., São Paulo, v. 12, n. 2, p. 316-328, junho 2009

\title{
Perversão sexual, ética e clínica psicanalítica*
}

\author{
Adelson Bruno dos Reis Santos \\ Paulo Roberto Ceccarelli
}

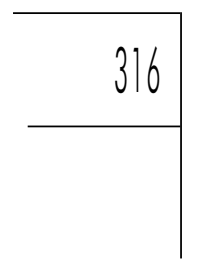

\begin{abstract}
Neste trabalho os autores propõem discutir um construto teórico-clínico - a perversão - de difícil consenso entre as diversas teorias que compõem o universo psicanalítico. Defende-se o "direito à diferença", como uma expressão legítima de uma forma de organização psíquica, e sustenta-se que toda tentativa de normatização e de transformação do sujeito em um "sujeito-teórico" constitui uma perversão de papel do psicanalista. Para os autores, a clínica da perversão reabre o debate sobre a disposição ética para a escuta, e coloca o psicanalista diante das moções pulsionais perversas que o habitam.
\end{abstract}

Palavras-chave: Perversão, ética, pulsão, neossexualidades

* Artigo baseado em Monografia de Conclusão do Curso de Graduação em Psicologia. A perversão sexual: por uma disposição ética para a clínica psicanalítica, Instituto de Psicologia da Pontifícia Universidade Católica de Minas Gerais - PUC-Minas, 2007. 
ARTIGOS

A sexualidade humana, em todas as suas múltiplas formas, variações e expressões, se constitui como um infindável campo para a investigação teórico-clínica. Teceremos, aqui, algumas considerações acerca de um construto teórico-clínico - a perversão - extremamente complexo, polêmico, e de difícil consenso entre as diversas teorias que compõem a "pólis psicanalítica". Estrutura? Desvio de uma norma? Solução? Aberração? Afinal, como definir a perversão sexual? Trata-se de algo abominável a ser censurado e punido em quaisquer circunstâncias, ou deve-se levar em consideração o direito à diferença como expressão legítima de uma forma de organização psíquica? Elisabeth Roudinesco (2007), em seu último livro, escreve que:

A perversão é um fenômeno sexual, político, social, físico, trans-histórico, estrutural, presente em todas as sociedades humanas [e questiona]: $\mathrm{O}$ que faríamos se não mais pudéssemos designar como bodes expiatórios - ou seja, como perversos - aqueles que aceitam traduzir por seus atos estranhos as tendências inconfessáveis que nos habitam e que recalcamos? (p. 15)

Ao dar uma dimensão histórica à perversão, Roudinesco nos remete à essência do pensamento freudiano sobre o tema, fazendo-nos refletir sobre nossas próprias moções pulsionais perversas.

Muitos são os tabus e os códigos de conduta presentes na sociedade ocidental que, até hoje, ditam uma normatização utópica para o desejo. A ideologia religiosa, por exemplo, sempre subjugou e restringiu as possibilidades de uma vivência sexual que levasse em consideração a visão psicanalítica de uma pulsão sexual infantil diversificada, anárquica, plural, parcial, bissexual e perversa, subjacente a toda e qualquer constituição psíquica. Do Código de Moisés aos dias atuais, o sexo sempre foi relegado pelas religiões ancoradas na tradição judaico-cristã a um estado inferior, passível de condenações, restrições e punições divinas e humanas.

No século XIX a ciência médico-psiquiátrica abarcou o saber sobre o sexo contribuindo, assim, para uma concepção normopata da sexualidade humana ligando, muitas vezes, loucura e sexualidade. Em consonância com a justiça, reprimia-se e punia-se o "sexo doente". A sexualidade foi criminalizada em nome da moral e dos bons costumes da "sociedade honesta". A família deveria ser, a todo custo, preservada dos ataques de lascívia dos "loucos sexuais". O ato sexual no lar tinha seus limites, devendo-se extirpar os desvios e respeitar a "natureza sexual" e a "sexualidade sadia". O submundo da sexualidade devia ser exercido fora do lar, podendo existir o sadio e o desvio, 


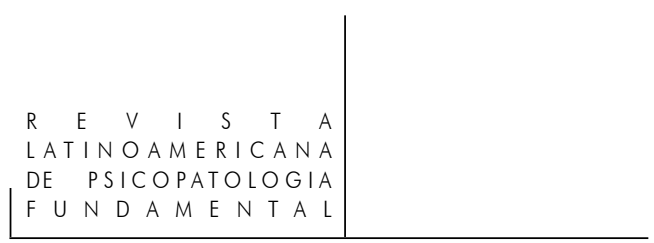

mas de formas separadas: eles não caberiam sob o mesmo teto. A sexualidade não tinha, portanto, "direito de escolha", sendo entendida como feita para a reprodução e para a manutenção da família. Tudo aquilo que se desviasse dessa norma era considerado antinatural.

À ciência interessava detectar os "perversos" e as "aberrações sexuais" exatamente para mantê-los à margem, para melhor conservar a integridade e a saúde dos indivíduos "normais". Krafft-Ebing (1886) e Havelock Ellis (1898) se destacaram entre os maiores cientistas do pensamento médico-positivista sobre as perversões no início do século XIX. Krafft-Ebing foi o primeiro a classificar clinicamente as psicopatias sexuais descrevendo o que chamou de "excitação da vida sexual por estímulos inadequados" (p. 31). Para ele, os desvios sexuais poderiam ser tratados e a normalidade atingida desde que reforçada pela força de vontade e pelo tratamento moral. Havelock Ellis (1898) questionou as posições de Krafft-Ebing dizendo que os fenômenos "normais" e a maioria das perversões sexuais são apenas exagerações dos instintos e das emoções que se encontram em estado de gérmen nos "seres humanos normais". "Enquanto ignoramos os limites da sexualidade normal, não somos capazes de fixar regras razoáveis para a sexualidade" (p. 22).

Embora o sentido que a psicanálise freudiana tenha dado ao termo perversão guarde diferenças em relação ao seu emprego pelo saber médico do século XIX, não podemos negar as semelhanças quanto à apreensão do significado desse termo nessas duas tradições de pensamento. As classificações e descrições que Krafft-Ebing e Havelock Ellis faziam das diversas formas de perversão sexual foram cuidadosamente examinadas por Freud e adotadas na elaboração dos "Três ensaios sobre a teoria da sexualidade" de 1905. Para uma melhor compreensão do pensamento freudiano relativo à perversão, achamos pertinente uma breve digressão das posições de Freud no que concerne à sexualidade. Para tanto, partimos da teoria da sedução em direção à revolução provocada pelo descobrimento do "efeito arrebatador de Édipo-Rei" (1897).

O ponto inovador da obra freudiana foi considerar não apenas que a sexualidade está presente desde a infância, mas, também, que esta sexualidade infantil será o esboço da sexualidade no adulto. Entretanto, este não era o pensamento de Freud no início de sua produção teórica. Ele não defendeu, a priori, a existência de uma sexualidade infantil. Propunha uma cena de sedução na qual a criança era invadida pela sexualidade do adulto, não sendo capaz de construir uma representação sexual para tal cena. Contudo, a teoria da sedução não resistiu por muito tempo ao trabalho intelectual de Freud. Na "Carta 69", de 1897, ele ressalta alguns dos fatores que contribuíram para que chegasse à seguinte conclusão: "não acredito mais em minha neurótica". Freud abandona, portanto, o atentado sexual como ponto de ancoragem das neuroses. 
Em 1897, na "Carta 71", como fruto de sua autoanálise, Freud revoluciona sua teoria pelo descobrimento do "efeito arrebatador de Édipo-Rei". A partir daí ele reconhece que as moções sexuais atuavam normalmente na criança desde a mais tenra idade, sem nenhuma necessidade de estimulação ou de sedução externa por parte de um adulto. Entretanto, cabe precisar que o que Freud, de fato, abandona, é a veracidade da cena de sedução. Ou seja, o que passa a contar não é a realidade factual, mas sim a realidade psíquica. Em alguns casos relatados pelas suas pacientes, a sedução, de fato, ocorrera; em outros, não. Mas, em ambos os casos, do ponto de vista do psiquismo infantil, a sexualidade é sempre despertada por uma sedução que vem de fora.

O complexo de Édipo será o organizador final da configuração sexual da vida adulta e, por isso, as escolhas de objeto nesta fase serão determinantes para a construção da identidade psicossexual. Freud (1905) conclui que a sexualidade humana é polimorficamente perversa e que, consequentemente, a disposição para a perversão é um dado originário e universal da pulsão sexual dos seres humanos. A partir daí as alterações orgânicas e as inibições psíquicas se desenvolverão em direção à conduta sexual dita "normal". No entanto, o que é chamado por Freud de "sexualidade normal" não deve ser confundido com a atitude normativa popular acordada à heterossexualidade como se esta fosse a única manifestação da sexualidade infantil que merecesse sobreviver na idade adulta. Ao postular que não há nada de natural na pulsão, Freud chama a atenção para a "flutuação periódica entre objeto normal e objeto invertido" (p. 146), o que faz com que a perversão seja uma das possíveis vicissitudes da pulsão, com regressão ou fixação a um estágio libidinal anterior. Porém, no decorrer de sua obra, Freud aprofunda sua compreensão da perversão procurando responder a essa questão a partir da situação da criança frente ao complexo de Édipo.

Podemos distinguir, na trajetória do pensamento freudiano sobre a perversão, três momentos essenciais de sua teorização. No primeiro, Freud afirma na "Carta 52" que "a histeria não consiste na rejeição da sexualidade, mas em uma rejeição da perversão". Isso fez com que afirmasse já nos "Três ensaios...", em 1905, e mais tarde em "Moral sexual civilizada e doença nervosa moderna", de 1908, que "a neurose é o negativo da perversão" (p. 196). O segundo momento estaria relacionado com a teoria do complexo de Édipo. E o terceiro momento formulado a partir de "O fetichismo" (1927), quando Freud define a recusa da castração (Verleugnung) como o mecanismo essencial da perversão.

Apoiar-se na realidade da castração para explicar a diferença anatômica entre os sexos é permanecer num registro arcaico. Assim, o perverso mantém como incerta a veracidade da castração, em vez de reconhecê-la numa inscrição imaginária. O perverso tenta convencer a si e aos outros de que detém o segredo do desejo sexual e o exibe em sua criação erótica. Mas que segredo é este? O se- 


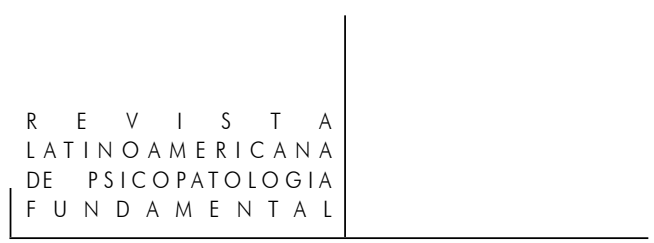

gredo é que não existe diferença alguma entre os sexos. Conscientemente o sujeito sabe que existem diferenças fundamentais, embora estas não tenham nenhuma função simbólica e não sejam nem causa nem condição do desejo sexual (McDougall, 1978).

Entre os principais pesquisadores da perversão na contemporaneidade destacamos Joyce McDougall, que amplia o referencial teórico freudiano adicionando-lhe suas próprias contribuições. Dona de um pensamento coerente e sólido, McDougall procura, sem sectarismo, sublinhar a importância de cada Escola Psicanalítica no que diz respeito à constituição da sexualidade humana. Em sua obra, a perversão é colocada como uma solução para os conflitos dilacerantes do ego. A autora analisa a perversão a partir, fundamentalmente, do sofrimento psíquico do sujeito. Através da introdução do conceito de "neossexualidades", sustenta que os arranjos sexuais, convencionalmente rotulados de perversos, são soluções infantis para conflitos psíquicos insuportáveis. É importante ressaltar que ela desenvolve sua teoria a partir da compreensão da perversão como movimento pulsional, algo da ordem do destino da pulsão e não como estrutura. Para ela, o único aspecto de uma fantasia que poderia legitimamente ser descrito como perverso seria a tentativa de impor a imaginação erótica a um outro que não consentisse nisso ou que não fosse responsável (McDougall, 1995).

A sexualidade infantil se constitui pelas representações simbólicas que, independentemente da anatomia, são criadas a partir do inconsciente biparental e do contexto sociocultural no qual o recém-nascido se encontra inserido. A atitude da criança em relação ao desejo se organiza em função do tipo de relacionamento que ela mantém com quem a introduz no simbólico. Ou o desejo será vivido como algo permitido integrando-se ao ego e abrindo caminho para a sexualidade adulta, ou, ao contrário, a criança vai vivê-lo como algo proibido, perigoso, implicado sempre num risco fantasmático de castração. A organização subjetiva dos pais pode levá-los a utilizar a criança para preencher suas próprias lacunas narcísicas. Neste caso, há o grande risco de que a criança não receba as ajudas indispensáveis para construir a alteridade, assim como a inelutável diferença dos sexos. Ou seja, lhe serão recusados os direitos a uma existência e a uma identidade psicossexual, enfim, o acesso ao desejo.

Por trás dessa realidade encontramos uma imagem materna temida e um pai castrado que cede o lugar a um outro, qual seja, ao fantasma do falo. A imagem fálica essencial para a compreensão e estruturação da identidade psicossexual é procurada compulsivamente no exterior. Esta busca insistente atesta a gravidade da falha simbólica. Este destino edípico seria tanto uma resposta aos problemas de identidade e de alteridade, quanto uma forma de evitar a angústia de castração, além de constituir uma maneira privilegiada de dar vazão às pulsões pré-genitais. Tudo isso pode gerar uma imagem frágil e prejudicada do corpo como 
um todo, o que deixa uma marca amalgamada à identidade de gênero e ao papel sexual.

É fatídico: todo ser humano tem que aceitar a dolorosa constatação de que nunca possuirá os dois sexos, e que sempre será a metade da totalidade sexual. A partir do momento em que os pais passam a ser reconhecidos em suas alteridades e em suas identidades sexuais diferentes, porém genitalmente complementares, a cena primária segundo a qual a sexualidade é algo terrível, que o amor é igual à catástrofe, castração e morte, se transforma. A "nova" cena internalizada torna-se uma aquisição psíquica que traz como prêmio o direito a um lugar na família, a um corpo e a uma sexualidade, ou seja, um lugar no simbólico.

Do ponto de vista desses sujeitos "perversos" seus comportamentos considerados desviantes são vivenciados como parte integrante do sentimento de identidade, mesmo tendo em vista a censura moral a propósito de seus quereres. Talvez seja uma questão de sobrevivência psíquica, de uma maneira de resguardar um sentimento de identidade psicossexual, bem como de manter um sentimento de eu ideal. A erotização do trauma torna-se, portanto, uma tentativa de elaborá-lo. A criança acopla ao mito universal do Édipo sua mitologia sexual privada. A necessidade de revestir de nova roupagem o ato sexual representa as soluções possíveis que o adulto em seu passado infantil foi capaz de encontrar diante das comunicações parentais contraditórias e insuficientes.

"Ninguém escolhe livremente os padrões e os limites que as neossexualidades impõem" (McDougall, 1995, p. 193). Um dos fatores que poderiam caracterizar o chamado perverso é justamente o fato de que ele não tem escolha. Para alguns indivíduos, tais práticas sexuais não despertam conflitos, uma vez que não são sentidas como compulsivas ou como condições exclusivas para o prazer sexual. Mas, há também os indivíduos que só têm roteiros fetichistas ou sadomasoquistas à disposição para empenharem-se em um relacionamento sexual. Sendo assim, as variações sexuais só se tornam problema na medida em que os indivíduos envolvidos a vivenciem como egodistônica. Contudo, qualquer que seja a modalidade sexual, esses indivíduos raramente abandonam suas soluções eróticas. "Perder o único sistema de sobrevivência sexual de que dispõem seria o equivalente à castração" (p. 188).

Na sexualidade perversa o que está em jogo é a angústia originária, o perigo de desaparecer. Em face desta morte psíquica, o frágil ser infantil inventará o que quer que seja a fim de evitá-la. Coagido entre o desejo de viver e a impossibilidade de realizar este desejo sem violência, encontra na neossexualidade o cenário e a ação suscetíveis de contê-la e, paralelamente, a expressão erótica que permite não somente a existência de uma vida sexual, ainda que restrita, mas também o contato com o outro, ainda que parcial. 


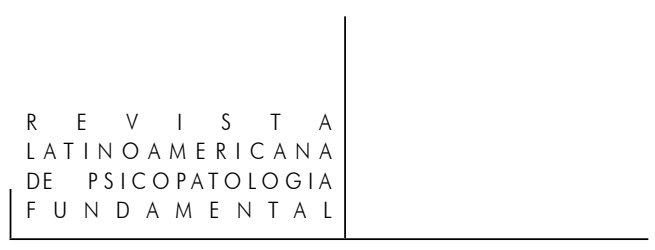

No agir perverso é o outro quem vai oferecer a prova de que a castração não faz mal, de que a diferença entre os sexos não é a causa do desejo sexual e de que a cena primitiva é como o autor do roteiro a criou. Há, assim, uma solução mágica da tensão interna, o que faz com que a procura compulsiva por parceiros torne-se uma necessidade urgente. "O papel do outro na perversão é permitir o contorno da angústia fálico-edipiana" (McDougall, 1982, p. 208).

Uma outra tentativa de compreensão do fenômeno perverso foi proposta pelo psicanalista norte-americano Robert Stoller. Stoller (1984, 1985, 1986, 1993) entende a perversão como uma passagem ao ato, sendo este ato perverso uma "cura" instantânea do trauma infligido pela castração. Diante da impossibilidade de que alguém escape à castração, a questão central colocada por Stoller é se existiria alguma manifestação erótica que não seria, em sua origem, perversa. Nesta perspectiva, o que deve ser, de fato, considerado perversão é o desejo de fazer mal ao objeto, humilhá-lo, degradá-lo. Humilhando, o perverso se vinga da humilhação a que foi submetido. A perversão é uma neurose erótica; uma forma erótica do ódio. O fantasma que sustenta o ato perverso é o de vingança que transforma o traumatismo (da criança) no triunfo do adulto.

Para Stoller, a origem da perversão deve ser procurada nas dificuldades encontradas pelo sujeito na construção da psicossexualidade, sobretudo no que se refere aos elementos masculinos e femininos presentes nesta construção. Os fantasmas criados pelos perversos para salvaguardar o prazer revelam-se ser formas de atuações da angústia e do ódio. Enfim, Stoller compreende a perversão como a produção de um cenário onde, através do fantasma, algo - o trauma - é atuado. Entretanto, qualquer enredo apresentado é sempre condenado ao fracasso, pois são sempre repetições e nunca elaborações.

Tais reflexões nos levam a concluir que a clínica da perversão requer uma disposição particular por parte do analista, para acompanhar o sujeito pela repetitiva e tortuosa trilha da sexualidade pré-genital de volta aos pontos de fixação da libido. A partir disso, uma questão central é a de saber, como afirma J. Dor (1991), se, de fato, "esta estrutura psíquica [a perversão] constitui uma organização definitiva" na qual "o perverso passa pelo enquistamento de toda a economia do desejo, que contribuirá para a instalação de uma fixação psíquica irreversível" (p. 30). Ora, o perverso da teoria lacaniana, instalado em uma posição psíquica irreversível, leia-se inanalisável, é o mesmo perverso do qual nos fala Freud? Ele seria mesmo inanalisável ou este axioma se justificaria por uma insuportabilidade de escuta por parte do analista? Em que medida os diferentes construtos teóricos inibem ou propiciam a disposição do analista para a escuta do sujeito perverso? Corremos o risco de usar nossa teoria como defesa e recuo diante da problemática perversa? 


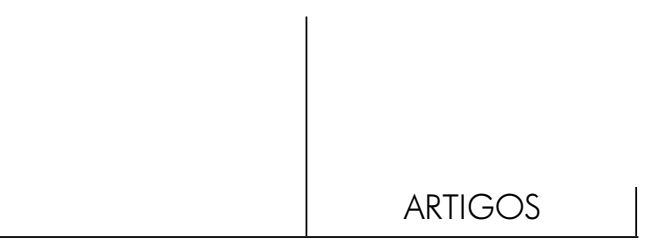

É comum escutarmos, nos meios psicanalíticos, que o perverso raramente procura uma análise. Isto faz sentido se considerarmos a prática da perversão como capaz de assegurar o gozo. O fato de os sintomas serem sentidos como prazerosos acabaria sendo um fator complicador no tratamento psicanalítico das perversões. Esta seria a dificuldade maior para a clínica da perversão. Mas, e aqueles que nos procuram? Rejeitá-los, a priori, caracterizaria "a perversão do outro lado do divã" (Ceccarelli, 2004) constituída de múltiplas faces e manifestada através, por exemplo, da imposição de uma teoria como defesa contra a escuta.

Transformar a teoria psicanalítica em uma seita e edificar construtos dogmáticos é incorrer no risco de uma normatização para a circulação do desejo. Não podemos desconsiderar a pluralidade de expressões que envolvem o enigma do sexual. Não existe uma forma única de travessia edípica e tampouco um modelo único de produção de alteridades. Não podemos correr o risco de transformar o sujeito em um "sujeito teórico". Sobre os "perversos inanalisáveis" que procuram análise, mais importante do que provar se a teoria se aplica a esses casos é saber se é possível ao analista escutá-los. É fundamental saber se o analista se dispõe a transformar seus motivos em demanda de análise. Não é que o perverso não seja analisável. Talvez seja a teoria que sustenta, para o analista, a constituição do sujeito perverso, que não contempla a análise dessa manifestação da sexualidade (Ceccarelli, 2005).

A escuta do perverso sempre nos confronta às questões éticas. As formas de manifestações perversas parecem nos colocar diante de posturas aéticas, o que, contratransferencialmente, nos declina da escuta psicanalítica, o que pode afastar o perverso da clínica. A disposição para a escuta do perverso implica reconhecer sua forma possível de sobrevivência psíquica. Entretanto, devemos estar atentos a uma linha tênue que separa o acolhimento e a escuta da benevolência e condescendência em relação àquilo que se escuta de um paciente perverso. "A clínica da perversão pode muitas vezes exigir do analista que experimente a máxima exigência ética da psicanálise, que pressupõe a neutralidade e a abstinência" (Ferraz, 2000, p. 8). Caso contrário, o paciente pode buscar imobilizar o analista, conduzindo-o ao lugar de espectador do cenário de suas relações objetais perversas.

As reações contratransferenciais requerem do analista uma habilidade especial, pois ele tanto pode ser seduzido pelo cenário perverso retratado pelo paciente, como pode ser incapaz de identificar-se minimamente com ele. Trata-se, na prática, de um difícil desafio lançado ao analista, pois a clínica da perversão impõe a ele o confronto com sua própria sexualidade infantil. Basta-nos lembrar de que sob uma superfície "neurótico-normal" conservamos os traços da criança "perverso-polimorfa".

Rev. Latinoam. Psicopat. Fund., São Paulo, v. 12, n. 2, p. 316-328, junho 2009 


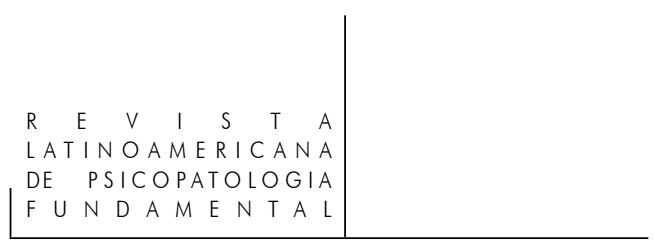

Qual seria, então, o objetivo do analista em sua condução clínica? Neste caso, o único objetivo é o de acompanhar seus pacientes na tentativa de compreensão de suas dinâmicas psíquicas para, então, poder reconhecer melhor os seus desejos, logo, suas escolhas e seus atos (McDougall, 1995). Não cabe ao analista qualquer exigência de transformação rumo à pretensa normalidade, pois não existe, a priori, nenhuma forma de sexualidade que constitua uma garantia contra distúrbios psicológicos. Trata-se, nesta perspectiva, de ultrapassar a lógica de um juízo de valor moral para levar em consideração a economia psíquica envolvida nas chamadas perversões sexuais.

Nos últimos anos, muito se tem escrito acerca da ética da prática psicanalítica. Entretanto, temos fracassado em examinar em que medida nossa teoria e nossa prática são afetadas pelos juízos de valor de nossos teóricos e clínicos" (McDougall, 1995, p. 235). Freud talvez acreditasse que os psicanalistas, uma vez analisados, estariam completamente livres de julgamentos morais em relação a seus analisandos. Não seria esta uma esperança ingênua? Será mesmo possível conceber tal liberdade em relação aos juízos de valor pessoais? Como é que eles afetam a construção de nossas teorias psicanalíticas relativas aos comportamentos sexualmente desviantes? Qual o efeito desses juízos de valor sobre o nosso trabalho clínico? É possível existir algum ideal especificamente psicanalítico, ou seja, 324 acima dos inevitáveis valores socioculturais, políticos e históricos? (McDougall, 1995).

Para McDougall (1995) não devemos julgar nossos pacientes, nem para aprová-los nem para reprová-los. A continuação da psicanálise poderia ficar em perigo se nossos objetivos declarados de fazer com que as pessoas se apercebam mais de seus conflitos antes inconscientes forem considerados desviantes e sentidos como ameaçadores para a ordem existente. A partir disso, na tentativa de articular uma atitude genuinamente psicanalítica diante do sujeito, parece justificável afirmar que os psicanalistas nunca deveriam intencionalmente impor seus sistemas de valores, suas preferências sexuais, suas opiniões políticas, as convicções teóricas de sua escola psicanalítica, a seus pacientes. Qualquer outra atitude constitui-se perversão do papel analítico. $\mathrm{O}$ analista que se acreditar normal, atribuindo-se assim o direito de preconizar normas aos seus analisandos, poderá tornar-se altamente tóxico para eles.

Alertamos, pois, para a necessidade de um olhar crítico que permitira aprofundar a compreensão daquilo que se convencionou denominar perversão sexual. Uma disposição para a escuta do sujeito dito perverso não se constrói na clausura do embotamento teórico que propicia uma posição normopata por parte de alguns analistas em relação a este sujeito. $\mathrm{O}$ analista não deve ser o espectador das atuações perversas de seu cliente. Porém, deve valer-se de sua postura neutra para não defender e ditar as regras para uma "vivência normal da sexualida-

Rev. Latinoam. Psicopat. Fund., São Paulo, v. 12, n. 2, p. 316-328, junho 2009 
de". Não podemos correr o risco de nos tornarmos uma comunidade sentenciosa, moralista e hipócrita, baseada em dogmas incapazes de serem revisitados na medida em que isso nos seja exigido pelas transformações atuais. "Não será, então, nossa principal perversão a crença de que temos a chave para a verdade?" (McDougall, 1995, p. 252).

Diante disso, o que fazer? Recusar-nos a aceitar esses pacientes em tratamento? Pedir que nos revelem de antemão se há alguma perversão sexual conduzindo-os à procura de ajuda analítica? Dispensá-los do tratamento assim que detectarmos algo "anormal"? Se assim o for, estaremos nos destituindo de nossa atitude analítica em benefício de nossos sistemas de valores, nossas preferências sexuais, opiniões políticas, convicções teóricas etc. A nós, analistas, cabe apenas o fascínio diante da observação de como "a relação do sujeito com seus objetos sexuais se estende ao conjunto de sua vida psíquica, de suas condutas, de suas atitudes morais, sociais, religiosas, éticas, estéticas e ideológicas, etc." (Chasseguet-Smirgel, 1984, p. 9).

\section{Referências}

Ceccarelli, P. R. A perversão do outro lado do divã. In: Portugual, A. M (Org.). Destinos da sexualidade. São Paulo: Casa do Psicólogo, 2004. p. 243-257.

. Perversão e suas versões. Reverso, Revista do Círculo Psicanalítico de Minas Gerais, Belo Horizonte, ano XXVII, n. 52, p. 43-50, 2005.

Chasseguet-Smirgel, J. Ética e estética da perversão. Porto Alegre: Artes Médicas, 1991.

Dor, J. Estruturas e clínica psicanalítica. Rio de Janeiro: Timbre, 1991.

Ferraz, F. C. Perversão. São Paulo: Casa do Psicólogo, 2000.

FReUd, S. (1895). Projeto para uma psicologia científica. In: Edição Standard Brasileira das Obras Psicológicas Completas de Sigmund Freud. Rio de Janeiro: Imago, 1976. v. 1.

. (1896). Carta 52. In: Edição Standard Brasileira das Obras Psicológicas

Completas de Sigmund Freud. Rio de Janeiro: Imago, 1977. v. 1.

. (1897). Carta 71. In: Edição Standard Brasileira das Obras Psicológicas

Completas de Sigmund Freud. Rio de Janeiro: Imago, 1977. v. 1.

. (1905). Três ensaios sobre a teoria da sexualidade. In: Edição Standard

Brasileira das Obras Psicológicas Completas de Sigmund Freud. Rio de Janeiro: Imago, 1972. v. 7.

. (1908). Moral sexual civilizada e doença nervosa moderna. In: Edição

Rev. Latinoam. Psicopat. Fund., São Paulo, v. 12, n. 2, p. 316-328, junho 2009 


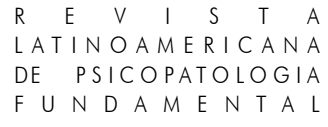

Standard Brasileira das Obras Psicológicas Completas de Sigmund Freud. Rio de Janeiro: Imago, 1976. v. 9.

. (1925). Algumas consequências psíquicas da distinção anatômica entre os sexos. In: Edição Standard Brasileira das Obras Psicológicas Completas de Sigmund Freud. Rio de Janeiro: Imago, 1976. v. 19.

. (1927). O fetichismo. In: Edição Standard Brasileira das Obras Psicológicas Completas de Sigmund Freud. Rio de Janeiro: Imago, 1976. v. 21.

. (1937). Análise terminável e interminável. In: Edição Standard Brasileira das Obras Psicológicas Completas de Sigmund Freud. Rio de Janeiro: Imago, 1976. v. 23. . (1940). A divisão do ego no processo de defesa. In: Edição Standard Brasileira das Obras Psicológicas Completas de Sigmund Freud. Rio de Janeiro: Imago, 1975. v. 23.

Havelock-Ellis.(1897). A inversão sexual. São Paulo: Companhia Editora Nacional, 1933.

(1898). O instinto sexual. São Paulo: Companhia Editora Nacional, 1933.

Herrman, F. Clínica psicanalítica: a arte da interpretação. São Paulo: Brasiliense, 1993. p. 146.

Krafft-Ebing, R. Von. (1886). Psicopatia sexual. Buenos Aires: El Ateneo, 1955.

Mazzieiro, J. B. A sexualidade criminalizada. Revista Brasileira de História, São Paulo, v. 18, n. 35, 1998.

McDougall, J. (1978). Em defesa de uma certa anormalidade. Tradução de Carlos Eduardo Reis. Porto Alegre: Artes Médicas, 1983.

Alves, 1989.

(1982). Teatros do eu. Tradução de Orlando Coddá. Rio de Janeiro: Francisco

. (1995). As múltiplas faces de Eros: uma exploração psicoanalítica da sexualidade humana. Tradução de Pedro Henrique Bernardes Rondon. São Paulo: Martins Fontes, 2001.

RoudinesCo, E. La part obscure de nous-même. Une histoire des pervers. Paris: Albin Michel, 2007. 248 p.

Stoller, R. La perversion et le désir de faire mal. In: La chose sexuel. Nouvelle Revue de Psychanalyse, Paris, n. 29, p. 147-172, maio 1984.

. Observing Erotic Imagination. New Haven: Yale University Press, 1985.

. (1986). La perversion: forme érotique de la haine. Paris: Payot, 2000.

Dynamiques des troubles erotiques. In: Les troubles de la sexualité. Paris: PUF, 1993. (Monographies de la Revue Française de Psychanalyse).

Rev. Latinoam. Psicopat. Fund., São Paulo, v. 12, n. 2, p. 316-328, junho 2009 
(Perversión sexual, ética y clínica psicoanalítica)

En este trabajo, los autores se proponen discutir una construcción teórico-clínica - la perversión - de difícil consenso entre las teorías que componen el universo psicoanalítico. Los autores defienden el "derecho a la diferencia" como expresión legítima de una forma de organización psíquica. Argumentan, además, que toda tentativa de normalización y de transformación de un sujeto en "sujeto-teórico" es una perversión del papel del psicoanalista. Para los autores, la clínica de la perversión reabre el debate sobre la disposición ética para la escucha del "perverso" y, al mismo tiempo, coloca al psicoanalista frente a las pulsiones perversas que lo habitan.

Palabras claves: Perversión, ética, pulsión, neo-sexualidades

(Perversion sexuelle, éthique et clinique psychanalytique)

Dans ce travail, les auteurs discutent une construction théorique-clinique - la perversion - dont l'appréhension est loin de faire consensus parmi les nombreuses théories qui composent l'univers psychanalytique. L'on y fait un plaidoyer au "droit à la différence" en tant qu'expression légitime d'une organisation psychique, tout en soulignant que toute tentative de normalisation et de transformation d'un sujet en "sujet-théorique" constituerait une perversion du rôle du psychanalyste. Pour les auteurs, la clinique de la perversion relance le débat sur l'éthique de l'écoute de la part de l'analyste et l'oblige à faire face aux motions pulsionnelles perverses qui l'habitent.

Mots clés: Perversion, éthique, pulsion, néo-sexualités

(Sexual perversion, ethics and psychoanalytic clinic)

In this article the authors discuss a theoretical-clinical construction-perversion - aware of the fact that very little consensus has been reached on this question among writers working with the various theories in the field of psychoanalysis. Many insist on the "right to be different" as a legitimate expression of psychic organization. They also stress that any attempt at setting down norms and trying to transform a subject into a "theoretical-subject" constitute a perversion of the psychoanalyst's role. For the authors of this article, the clinic of perversion brings up a debate on the ethics of listening and leads each analyst to come into contact with his or her own perverse drives.

Key words: Perversion, ethics, drive (instinct), neo-sexuality 


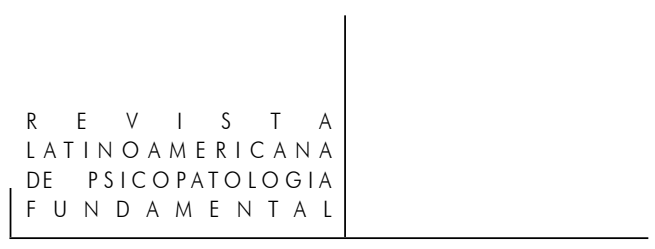

Citação/Citation: SAntos, A. B. R.; CecCARelli, P.R. Perversão sexual, ética e clínica psicanalítica. Revista Latinoamericana de Psicopatologia Fundamental, São Paulo, v. 12, n. 2, p. 316-328, jun. 2009.

Editor do artigo/Editor: Prof. Dr. Manoel Tosta Berlinck.

Recebido/Received: 15.3.2008/3.15.2008 Aceito/Accepted: 24.4.2008 / 4.24.2008

Copyright: () 2009 Associação Universitária de Pesquisa em Psicopatologia Fundamental/ University Association for Research in Fundamental Psychopathology. Este é um artigo de livre acesso, que permite uso irrestrito, distribuição e reprodução em qualquer meio, desde que $\mathrm{o}$ autor e a fonte sejam citados/This is an open-access article, which permits unrestricted use, distribution, and reproduction in any medium, provided the original author and source are credited.

Financiamento/Funding: Os autores declaram não ter sido financiados ou apoiados/The authors have no support or funding to report.

Conflito de interesses: Os autores declaram que não há conflito de interesses/The authors declare that has no conflict of interest.

\section{Adelson Bruno dos Reis Santos}

Psicólogo graduado pela Pontifícia Universidade Católica de Minas Gerais - PUC-MG (Belo Horizonte, MG, Brasil); aluno do Curso de Especialização em Teoria Psicanalítica da Universidade Federal de Minas Gerais - UFMG (Belo Horizonte, MG, Brasil).

Rua Além Paraíba, 241 - Lagoinha

31210-120 Belo Horizonte, MG, Brasil

Fone: (31) 8888-5836 / 3422-6895

e-mail: brunu_santos@yahoo.com.br

\section{Paulo Roberto Ceccarelli}

Psicólogo; psicanalista; doutor em Psicopatologia Fundamental e Psicanálise pela Universidade de Paris VII; membro da Associação Universitária de Pesquisa em Psicopatologia Fundamental (São Paulo, SP, Brasil); sócio do Círculo Psicanalítico de Minas Gerais (Belo Horizonte, MG, Brasil); membro da "Société de Psychanalyse Freudienne" (Paris, França); professor Adjunto III no Departamento de Psicologia (graduação e pós-graduação) da Pontifícia Universidade Católica de Minas Gerais - PUC-MG (Belo Horizonte, MG, Brasil).

Rua Aimorés, 1239/702

30140-071 Belo Horizonte, MG, Brasil

Fone: (31) 3274-2814 / 3213-2240 / 8792-5157

e-mail: pr@ceccarelli.psc.br / paulorcbh@mac.com

Homepage: www.ceccarelli.psc.br 